\title{
Facebook Discourse Analysis of US President Donald Trump
}

\author{
Assist. Prof. PhD. Tănase Tasențe \\ "Ovidius" University of Constanța, Romania \\ office@pluscommunication.eu
}

\begin{abstract}
SNSs, such as Facebook, focus all their attention more on politician communication than institutional communication (political party, government, parliament, presidency, etc.), which encourages the implementation of communication strategies for personalized campaigns. Thus, most of the times, one can reach the paradox that the image of the politicians is more visible than the image of the party, and the personalized aspects of the strategy of the political actor can even contradict the strategies of the communication structures of the political parties. Personalized communication in social media is also highlighted by the use of tagging, most political leaders using this tool to create image links with other political personalities or civil society (ministers, political groups of the same political party, political activists or even political opponents), seeking so that the original post is reproduced and disseminated by those mentioned, in their social groups, forming conversation communities with users that confirm existing convictions. This study focused on analyzing the Key Performance Indicators (KPIs) that facilitate Social Media Communication of Donald Trump, the President of United States of America (number of fans, types of posts, interactions etc.) and analyzing Donald Trump's Facebook speech and identify the most commonly used expressions in Social Media during the term of President. The monitoring period is 20.01.2017 - 16.08.2019.
\end{abstract}

Keywords. Donald Trump, US President, Social Media Communication, Web 2.0, online reactions, Facebook

Introduction

With the incorporation of SNSs into the strategies of political communication, the topdown model of unidirectional message reproduction and without the possibility of interaction between the protagonists and the recipients of the published contents entered into discussion. If in this traditional scheme, only politicians and political parties were able to put their voice in the public sphere, using traditional means of communication, the broad universe of social networks came to offer tools to change this paradigm from a communication

Thus, online social networks, such as Facebook, focus all their attention more on politician communication than institutional communication (political party, government, parliament, presidency, etc.), which encourages the implementation of communication strategies for personalized campaigns. Thus, most of the times, one can reach the paradox that the image of the politicians is more visible than the image of the party, and the personalized aspects of the strategy of the political actor can even contradict the strategies of the communication structures of the political parties.

Although it is assumed that SNSs will differentiate at the mechanism level from the classical communication channels, offering a much greater openness for debate, recent studies indicate that political leaders not only do not encourage conversation with their followers 
(Amado, Tarullo, 2016; Graham et al., 2014; Waisbord, 2015) but also that the communication they star in social networks does not promote the inclusion of new voices in discussions on public affairs (Calvo, Aruguete, 2018).

Moreover, according to a study by Raquel Tarullo (2018), it shows "a contradictory use of social networks that, although it allows political leaders to include in the communication to the addressee from the use of tags, links to other pages, hashtags and sharing publications originating from the walls of Other users' accounts to promote interaction, the nature of hashtags, tags and links to other pages approximates a reproduction of the communicative behavior that leaders star in traditional media". At the same time, it is shown that without a search for conversation or interaction based on the limited inclusion of the engagement features offered by Facebook, leaders replicate a model of personalist political communication, centralized in the leader's own figure.

Personalized communication in social media is also highlighted by the use of tagging, most political leaders using this tool to create image links with other political personalities or civil society (ministers, political groups of the same political party, political activists or even political opponents), seeking so that the original post is reproduced and disseminated by those mentioned, in their social groups, forming conversation communities with users that confirm existing convictions.

The same hypothesis was also demonstrated by Maria Pilgun and Galina Gradoselskaya (2015), who showed after a large study conducted in Russia that: (1) Politically active actors in Facebook are distributed in several clusters according to the political affiliations; (2) Communicative interaction between different clusters has the nature of conflict and (3) Proficiency level of sociolinguistic resources does not depend on belonging to certain cluster.

2 Analysis of Donald Trump's Facebook speech (January 20, 2017 - August 16, 2019)

\subsection{Research objectives}

O1: Analyzing the Key Performance Indicators (KPIs) that facilitate Social Media Communication of Donald Trump, the President of United States of America (number of fans, types of posts, interactions etc.)

O2: Analyzing Donald Trump's Facebook speech and identify the most commonly used expressions in Social Media during the term of President

\subsection{Methodology}

To achieve the research objectives, we will use both quantitative and qualitative methods. Thus, we will analyze the key performance indicators (KPIs) that facilitate Donald Trump's online communication, namely: the number of fans, the number of daily posts, the engagement rate, the dominant reactions, etc. At the same time, using the text analysis platform - https://www.online-utility.org/text/analyzer.jsp - we will centralize and analyze the most commonly used words and expressions on Donald Trump's Facebook, in order to determines the communication directions used during the term of president. The monitoring period is 20.01.2017 - 16.08.2019. 
2.3. Centralization and data analysis

Evolution of the number of the fans and the reactions of the fans

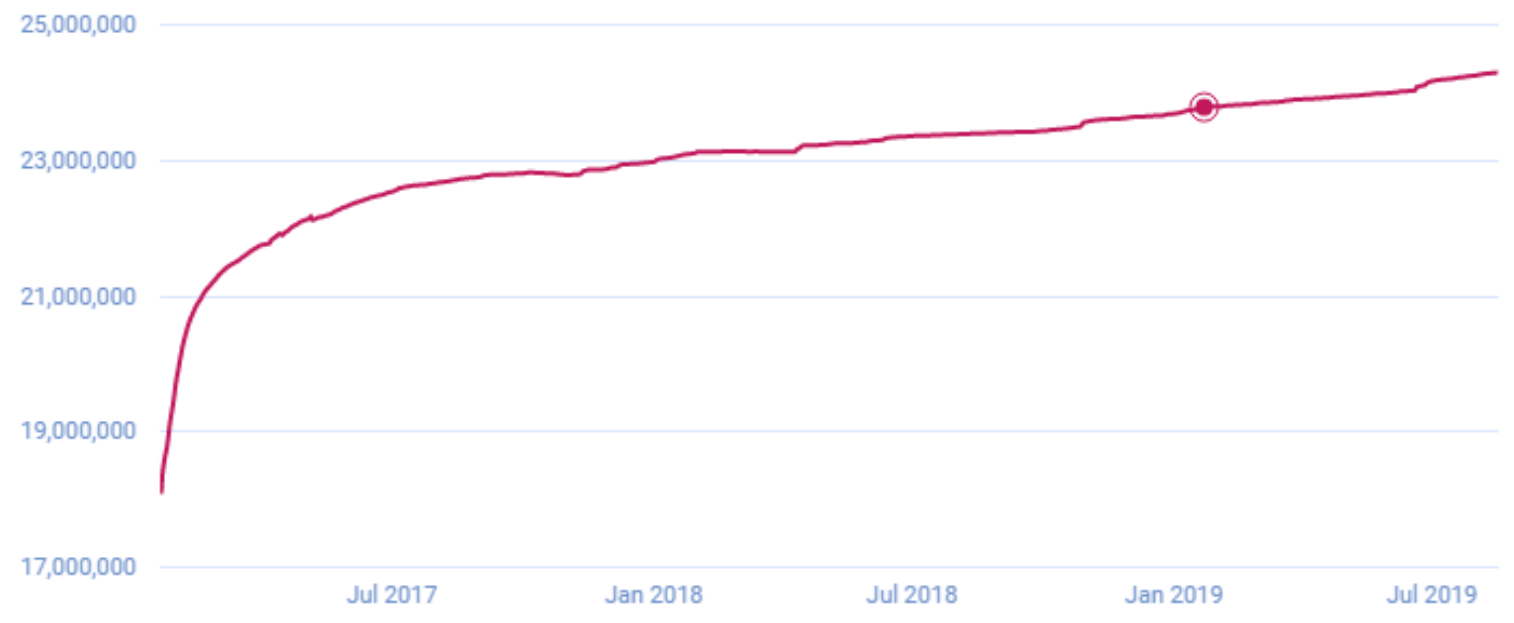

With the takeover of the President of the United States of America, on January 20, 2017, Donald J. Trump experienced an exponential increase in the number of fans on Facebook - from 18 million fans on January 20, 2017 to 21. millions of fans on February 22, 2017. Since then, the evolution of the number of fans has been constant, on August 16, 2019, Donald Trump's Facebook page has registered almost 24.3 million fans. Thus, we can see that in the first month of office (January 20, 2017 - February 22, 2017), Donald Trump increased by 3 million fans, and during February 23, 2017 - August 16, 2019 (2 years and 6 months), an increase of 3.3 million fans.

During the monitored period (January 20, 2017 - August 16, 2019), Donald Trump posted on his Facebook page 5,007 posts, of which: $36.9 \%$ video, 30.5\% photos, $18.5 \%$ status, $14 \%$ links. The advertising activity was intense, the rate being 10 posts per day, and the relatively high engagement rate, $2.7 \%$.

\begin{tabular}{l|lllll}
\hline Type & Total & $\begin{array}{l}\text { Avg. } \\
\text { Reactions }\end{array}$ & $\begin{array}{l}\text { Avg. } \\
\text { Comments }\end{array}$ & Avg. Shares & $\begin{array}{l}\text { o Total } \\
\text { interactions / } \\
\text { Post }\end{array}$ \\
\hline Status & 927 & 54,349 & 6,370 & 4,429 & 74,447 \\
Pictures & 1,529 & 57,542 & 5,782 & 6,806 & 80,033 \\
Links & 703 & 34,856 & 3,829 & 4,713 & 49,899 \\
Videos & 1,848 & 41,621 & 6,810 & 7,220 & 64,386 \\
\hline Total & $\mathbf{5 , 0 0 7}$ & $\mathbf{4 7 , 8 9 0}$ & $\mathbf{5 , 9 9 6}$ & $\mathbf{6 , 2 2 5}$ & $\mathbf{6 8 , 9 9 3}$ \\
\hline
\end{tabular}

Text analyzer - most frequent phrases used by Donald Trump

For analysis, we will only consider expressions that contain at most 4 words, to determine the key messages most commonly used in Donald Trump's Facebook speech. During the mentioned period, in the 5,007 posts, Donald Trump uses 147,664 words, which means, on average, 29.5 words per post and a number of 11,802 sentences, which represents an average of 2.36 sentences per post (relatively long posts). 
The Democrats, Donald Trump's opposition party, appear in the president's speech, on the Facebook page, 429 times (in 413 posts) out of a total of 5,007 posts (8.57\%), and his party, Republicans, 109 times out of a total of 5,007 posts (2.18\%). Moreover, most often we can see the term Democrats mentioned in the following expressions: "the radical democrats" (22 times), "the democrats wasted 2 years and \$25 million" (3 times), "could not be more clear democrats produce mobs" ( 3 times) or "the democrats raised millions off a lie" ( 3 times). On the other hand, Donald Trump most often mentions the term Republicans in the following terms: "with republican members of the senate" (10 times) and "a vote for republicans is a vote" (4 times).

\begin{tabular}{l|crrrrrrr}
\hline Words & Likes & Comments & Shares & Love & Haha & Wow & Sorry & Anger \\
\hline Democrats & 35247 & 5647 & 6463 & 3813 & 1211 & 249 & 328 & 1490 \\
Republicans & 38789 & 6312 & 5018 & 4459 & 1049 & 169 & 267 & 827 \\
Republicans \& & 39762 & 6310 & 5719 & 4595 & 932 & 189 & 228 & 995 \\
Democrats & & & & & & & & \\
\hline
\end{tabular}

When he used the term "Democrats" in his posts, we can see an average interaction rate of $0.23 \%$ and an average of the reactions, as follows: 35,247 likes per post, 5,647 comments per post, 6,463 shares per post, 3,813 love, 1,211 haha, 249 wow, 328 sorry and 1,490 anger .

On the other hand, the term "Republicans" generated an average interaction rate of $0.25 \%$ and an average of reactions, as follows: 38,789 likes per post, 6,312 comments, 5,018 shares, 4,459 love reactions, 1,049 haha, 169 wow, 267 sorry and 827 anger.

Both parties - "Democrats" and "Republicans" - are used in the same posting, in 41 of the cases, generating an interaction rate of $0.26 \%$. At the same time, the average fan reaction per post is as follows: 39,762 likes, 6,310 comments, 5,719 shares, 4,595 love, 932 haha, 189 wow, 228 sorry and 995 anger.

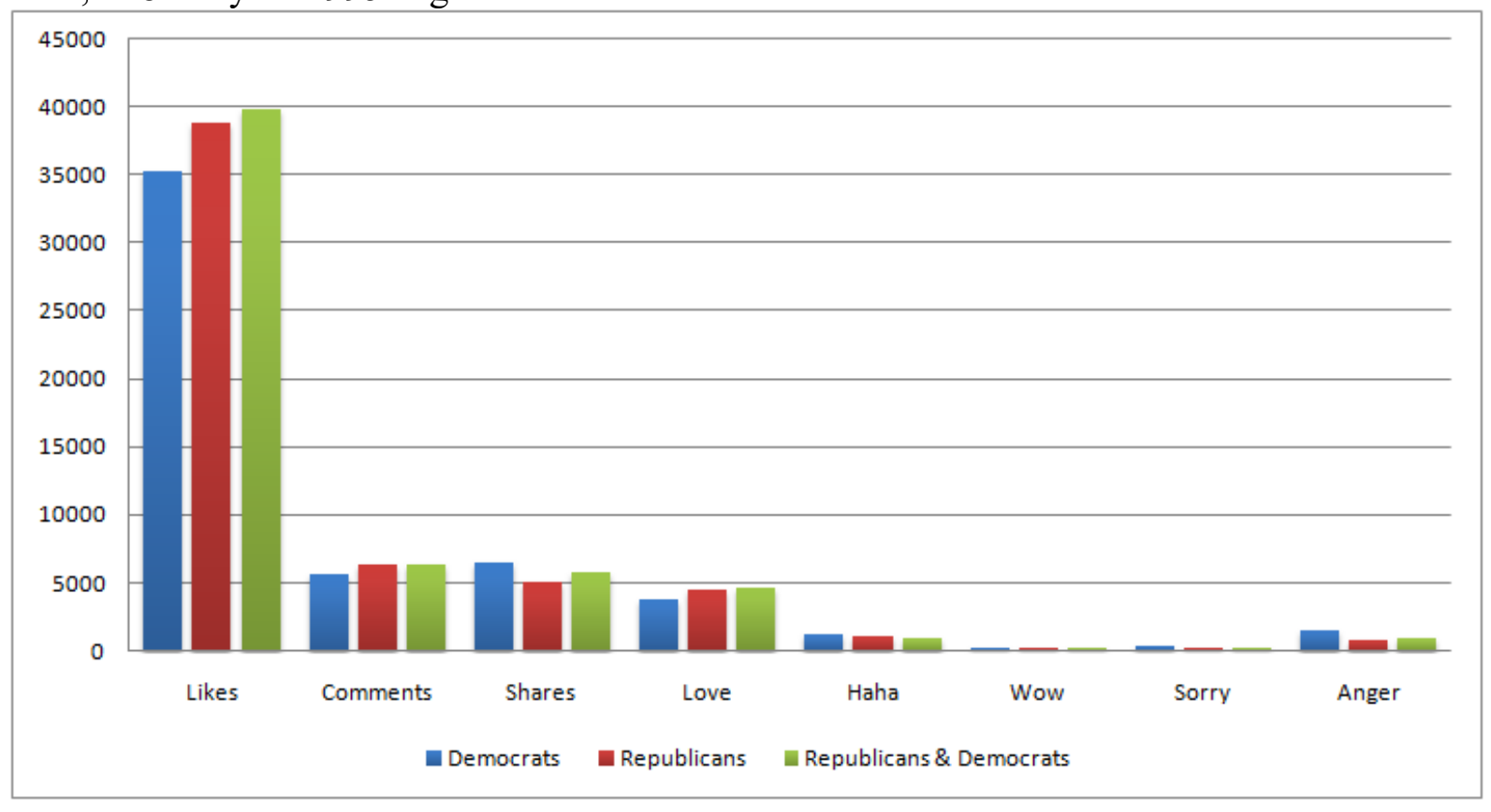

From the chart above, we can see that when he used the term "democrats", there was a negative reaction among the fans (anger, sorry and haha), and when he used the term "republicans", love reactions are more common. On the other hand, stronger interaction is 
when, in the same posts, both terms - "Republicans" and "Democrats" are used. In this case, we can see an increase in the rate of likes and loves.

\begin{tabular}{l|ll}
\hline No. & Top phrases containing 4 words (without punctuation marks) & Occurrences \\
\hline 1. & make america great again & 133 \\
2. & of the united states & 67 \\
3. & at the white house & 64 \\
4. & vice president mike pence & 60 \\
5. & trump's schedule for wednesday & 60 \\
6. & trump's schedule for tuesday & 56 \\
7. & the fake news media & 56 \\
8. & first lady melania trump & 54 \\
9. & join me live in & 54 \\
10. & travel to washington & 52 \\
11. & trump's schedule for thursday & 52 \\
12. & for a \#maga rally & 50 \\
13. & travel to washington d & 50 \\
14. & meeting with secretary of & 50 \\
15. & trump's tentative schedule for & 49 \\
16. & crowd for a \#maga & 49 \\
17. & great crowd for a & 49 \\
18. & with the secretary of & 48 \\
19. & with vice president mike & 48 \\
20. & trump's schedule for friday & 46 \\
21. & bilateral meeting with the & 45 \\
22. & to the white house & 42 \\
23. & america great again rally & 42 \\
24. & in the history of & 42 \\
25. & for the american people & 41 \\
26. & trump's schedule for monday & 41 \\
27. & with secretary of state & 41 \\
28. & with the president of & 40 \\
29. & the prime minister of & 39 \\
30. & meeting with secretary & 39 \\
31. & expanded bilateral meeting with & 39 \\
32. & receives daily intelligence briefing & 39 \\
33. & meeting with prime minister & 38 \\
34. & lunch with vice president & 36 \\
\hline & & \\
\hline
\end{tabular}

Viewed from the perspective of the topics most commonly used in the Social Media discourse, we can see that the slogan in the electoral campaign - "Make America great again" was retained during the term of office, being used in 133 posts, and the abbreviation of the slogan - "MAGA rally" - in 50 posts. On the other hand, we can see that the communicators are posting the President's program for each day, and most often we can see posts in which the program is mentioned on Wednesday (60 mentions), on Tuesday (56 mentions), on Thursday ( 52 mentions) and Friday (46 mentions). At the same time, US Vice President Mike Pence is mentioned by Donald Trump in 60 posts and First Lady Melania Trump in 54 posts. The topic 
of the campaigns regarding "fake news" is mentioned during the term of President, in 56 posts, and the invitation to follow the live made on Facebook appears in 54 posts.

Conclusions

Social Media has managed to give a strong voice to the politicians, who cannot be restrained by the censorship of traditional media institutions. Moreover, we can see that Facebook pages have managed, at many times, to be stronger than traditional media channels. For example, Donald Trump has managed to exponentially increase the number of fans on Facebook immediately after taking the Presidency, and his videos have generated even 11.3 million views ${ }^{1}$, in the context where, for example, Fox News manages to have a prime time audience of $2,446,000$ total views ${ }^{2}$.

At the same time, we can see that Donald Trump uses his strategy of attacking opponents more often than posts that present his Administration's achievements or mention the Republican Party. Thus, from our study, we observe that the US President mentions the opposition party 4 times more often (in posts in which he attacks them - eg "the radical democrats", "the democrats wasted 2 years and \$25 million", "could not be more clear Democrats produce mobs" or "the Democrats Raised millions off the lie") compared with posts in which he mentions Republicans. Looking at the reactions of the public, we can see that when he mentions his opposition party - Democrats - there are many negative reactions to them (anger, sorry, haha and negative comments), and when the Republican activities are mentioned, the dominant emotions are positive (love and like).

Also, Donald Trump continues the communication strategy during the campaign and during the term of President, often using the slogan "Make America Great Again" or shortened "MAGA". We can often see that the public communication strategies are often published on Facebook by the President's daily program, thus highlighting the transparency, as a primary value, of the Donald Trump Administration, but also promoting joint activities with First Lady Melania Trump and US Vice President Mike Pence.

\section{$4 \quad$ References}

[1] Amado, A., Tarullo, R. (2016). "Las redes sociales en la comunicación política: ¿comunicación unidireccional o conversacional?” Contratexto. 0(24), 97-111.

[2] Aruguete, N., Calvo, E. (2018). "Time to \#protest: Selective exposure, cascading activation, and framing in social media". Journal of Communication, 68(3), 480-502.

[3] Graham, T., Broersma, M., Hazelhoff, K., y Van 't Haar, G. (2013). "Between broadcasting messages and interacting with voters: The use of Twitter during the 2010 UK general election campaign". Information, Communication \& Society, 16(5), 692716.

[4] Waisbord, S. (2015). "United and fragmented: Communication and media studies in Latin America". Journal of Latin American Communication Research, 4(1), 1-23.

[5] Tarullo, R. (2019). "The strategic use of interaction in the communication of argentinean politicans in Facebook". Global Media Journal

[6] Pilgun, M., Gradoselskaya, G. (2015). "Political communication on facebook: Russian Case". Revista Latina de Comunicacion Social.

\footnotetext{
${ }^{1}$ http://www.facebook.com/153080620724/posts/10158514034445725

${ }^{2} \mathrm{https}$ //www.adweek.com/tvnewser/q1-2019-ratings-fox-news-continues-its-reign-as-cables-most-watchednetwork/398384/
} 